\title{
Two Genes Affecting Glucarate Utilization in Escherichia coli K12
}

\author{
By A. M. ROBERTON, $\uparrow$ P. A. SULLIVAN, + M. C. JONES-MORTIMER \\ AND H. L. KORNBERG* \\ Department of Biochemistry, University of Cambridge, Tennis Court Road, \\ Cambridge CB2 $1 Q W$
}

(Received 28 September 1979)

\begin{abstract}
D-Glucarate is transported into Escherichia coli $\mathrm{K} 12$ by an inducible system at an apparent rate of 7 to $15 \mathrm{nmol} \mathrm{min}^{-1}$ (mg dry mass) ${ }^{-1}$. The apparent $K_{\mathrm{m}}$ for uptake is $16 \mu \mathrm{M}$. The system is induced by growth on glucarate or glycollate. Galactarate competes with glucarate for the uptake system. A mutation $(\operatorname{gar} A)$ was isolated in which activities of glucarate transport and glucarate dehydratase and the ability to grow on glucarate or galactarate are all impaired. The mutation maps at min 16 . Another mutation of indistinguishable phenotype is probably a deletion of the genes $\operatorname{gar} B$ and $\operatorname{ton} A$ at $\min 3 \cdot 5$.
\end{abstract}

\section{INTRODUCTION}

Escherichia coli K12 metabolizes D-glucarate (the 1,6-dicarboxylic acid derivative of glucose) by a pathway involving the enzymes D-glucarate dehydratase (EC 4.2.1.40), 2-keto-3-deoxy-D-glucarate aldolase (EC 4.1.2.20) and tartronate-semialdehyde reductase (EC 1.1.1.60) (Blumenthal \& Fish, 1963). This paper examines the properties of the glucarate transport system and of mutants in which this transport system is deficient.

\section{METHODS}

Organisms. The strains of $E$. coli used and their provenance are listed in Table 1. The genetic symbols are those of Bachmann et al. (1976), except garA and garB. Bacteriophage P1kc was obtained from M. D. Yudkin and T5 from P. Oliver.

Growth. Cultures were grown aerobically at $37^{\circ} \mathrm{C}$ either in double-strength nutrient broth, or in defined medium containing salts (Ashworth \& Kornberg, 1966), an energy source equivalent in carbon to $10 \mathrm{~mm}$ hexose, and L-amino acids ( 40 to $80 \mu \mathrm{g} \mathrm{ml}^{-1}$ ) as required. Growth was monitored by diluting samples and measuring their absorbance at $680 \mathrm{~nm}$ in a $1 \mathrm{~cm}$ light path spectrophotometer cuvette. An $A_{680}$ of 1.0 was taken as equivalent to $0.7 \mathrm{mg}$ dry mass cells $\mathrm{ml}^{-1}$. The genetical methods employed were those described by Miller (1972).

Measurement of $\left[{ }^{14} \mathrm{C}\right]$ glucarate transport. Bacteria were harvested from growing cultures by centrifuging at $2000 \mathrm{~g}$ for $7 \mathrm{~min}$, washed in $50 \mathrm{~mm}$-sodium phosphate buffer $\mathrm{pH} 7.2$ at room temperature, and suspended in $2 \mathrm{ml}$ buffer containing chloramphenicol $\left(100 \mu \mathrm{g} \mathrm{ml}^{-1}\right)$. Washed bacteria $\left(0.7 \mathrm{mg} \mathrm{ml}^{-1}\right.$ final concentration unless otherwise stated) and buffer containing chloramphenicol were shaken for $3 \mathrm{~min}$ at $\left.30{ }^{\circ} \mathrm{C} .{ }^{14} \mathrm{C}\right]$ Glucarate $(91 \mathrm{nmol})$ was added (giving $1 \mathrm{ml}$ final volume) and 0.1 or $0.2 \mathrm{ml}$ samples were removed at appropriate times between 10 and $70 \mathrm{~s}$. The samples were filtered, the cells were washed and the incorporated radioactivity was measured as described by Bächi \& Kornberg (1975).

Enzyme measurements. Cell-free extracts were prepared from cells by sonication for 1 to $2 \mathrm{~min}$ (with intervals for cooling) in $50 \mathrm{mM}$-Tris/ $\mathrm{HCl}$ buffer $\mathrm{pH} 7 \cdot 5$, followed by centrifugation at $27000 \mathrm{~g}$ for $15 \mathrm{~min}$ at $0{ }^{\circ} \mathrm{C}$.

$\dagger$ Permanent address: Department of Biochemistry, University of Auckland, Private Bag, Auckland, New Zealand.

$\ddagger$ Permanent address: Department of Biochemistry, University of Otago, Box 56, Dunedin, New Zealand. 
Table 1. Strains of Escherichia coli used

\begin{tabular}{|c|c|c|}
\hline Strain & Genotype & Reference or source \\
\hline \multicolumn{3}{|l|}{ Hfr strains } \\
\hline $\mathrm{K} 1.1 .4$ & met thy glt A pps (PO1) & Laboratory stock \\
\hline KL16.21 & $p t s M$ ptsF $(\mathrm{PO} 45)$ & Ferenci \& Kornberg (1974) \\
\hline KL208 & $\mathrm{gar}^{+}(\mathrm{PO} 43)$ & Low (1973) \\
\hline PB1 139 & $\operatorname{gar}^{+} \operatorname{galT}(\mathrm{PO} 1)$ & P. L. Pergquist \\
\hline PB99 & gar met (PO43) & P. L. Bergquist \\
\hline CSH68 & $\mathrm{gar}^{+}$met mtl mal (PO58) & P. L. Bergquist \\
\hline Hfr Cavalli & gar met $(\mathrm{PO} 2 \mathrm{~A})$ & Bachmann (1972) \\
\hline W1895 & gar met $(\mathrm{PO} 2 \mathrm{~A})$ & Bachmann (1972) \\
\hline CS101 & gar $B$ met tonA $(\mathrm{PO} 2 \mathrm{~A})$ & Bachmann (1972) \\
\hline K10 & $\operatorname{gar} B \operatorname{ton} A(\mathrm{PO} 2 \mathrm{~A})$ & Bachmann (1972) \\
\hline $\mathrm{P} 4 \mathrm{X}$ & gar $B^{+}$met $(\mathrm{PO} 3)$ & Bachmann (1972) \\
\hline JM1343 & gar $B$ ton $A$ mel ilv (PO2A) & $\begin{array}{l}\mathrm{Mel}^{-} \text {from JM1090 (Henderson } \\
\text { et al., 1977) }\end{array}$ \\
\hline JM 1447 & garB tonA mel ilv ara (PO2A) & Ara- from JM1343 \\
\hline JM 1448 & garB tonA mel ilv thr leu (PO2A) & P1.K2.1t $\times$ JM1447 \\
\hline AT997 & $\operatorname{gar}^{+}$dap $C(\mathrm{PO} 45)$ & Bukhari \& Taylor (1971) \\
\hline JM1056 & $g a r^{+}$dapD $(\mathrm{PO} 45)$ & AT982 (Bukhari \& Taylor, 1971) \\
\hline \multicolumn{3}{|l|}{ F strain } \\
\hline W6 & gari met & Bachmann (1972) \\
\hline \multicolumn{3}{|l|}{$\mathrm{F}^{-}$strains } \\
\hline $\mathrm{K} 2.1 .2 .22$ & $\mathrm{gar}^{+}$met his thr leu ppc pps ptsG str & Laboratory stock \\
\hline $\mathrm{K} 2.1 \mathrm{t}$ & gar his arg thr leu $x y l$ pps galP mglP str & Brice \& Kornberg (1967) \\
\hline AR109 & garA met his thr leu ppc pps ptsG str & $\begin{array}{l}\mathrm{K} 2.1 .2 .22 \text { by resistance to } \\
\text { glucarate on acetate }\end{array}$ \\
\hline AR 114 & gar $A$ his arg thr leu pps ptsG str & AR 109 by transduction \\
\hline AR115 & gar $^{+}$his arg thr lell pps ptsG str & $\mathrm{K} 2.1 .2 .22$ by transduction \\
\hline AR 116 & garA arg thr leu pps ptsG ptsF pts $M$ str & KL16.21 ×AR 114 \\
\hline AR 127 & gar $A$ arg galT ptsG str & PB1139 × AR 116 \\
\hline PB68 & gart $^{+}$pro leu lac $Y$ thi mtl xyl galK2 ara str & P. L. Bergquist \\
\hline AB 1157 & gart pro thr leu arg his lac str & B. M. Wilkins \\
\hline
\end{tabular}

Glucarate dehydratase was measured essentially by the method of Blumenthal (1966) using a $10 \mathrm{~min}$ incubation at $30^{\circ} \mathrm{C}$. The assay mixture (final volume $2 \mathrm{ml}$ ) contained $20 \mu \mathrm{mol}$ potassium glucarate, $160 / \mathrm{mol}$ Tris $/ \mathrm{HCl}$ buffer $\mathrm{pH} 8.0,20 \mu \mathrm{mol} \mathrm{MgSO}_{4}$ and cell-free extract containing about $5 \mathrm{mg}$ protein. Protein was determined by the Lowry method.

Preparation of $\left[{ }^{14} \mathrm{C}\right]$ glucarate. The oxidation of glucose to glucaric acid was based on the method described by Mehltretter (1963), suitably scaled down. [U- ${ }^{14} \mathrm{C}$ ]Glucose [ $25 \mathrm{mg}, 21 \mu \mathrm{Ci} \mathrm{mg}^{-1}\left(0 \cdot 78 \mathrm{MEq} \mathrm{mg}^{-1}\right)$; The Radiochemical Centre, Amersham] was heated at $75{ }^{\circ} \mathrm{C}$ for $2 \mathrm{~h}$ with $0.02 \mathrm{ml}$ sodium nitrate $(0.25 \mathrm{mg})$ and $0.32 \mathrm{ml}$ conc. nitric acid. The excess nitric acid was removed by vacuum, and the crude glucaric acid was dissolved in water. One quarter of this was applied in a strip to Whatman 3MM chromatography paper and run in a high-voltage electrophoresis apparatus $(5 \mathrm{kV}, \mathrm{pH} 6.5,12 \mathrm{~min})$. Three major bands were found by autoradiography, and the one corresponding to glucaric acid was eluted with water and reapplied to chro-

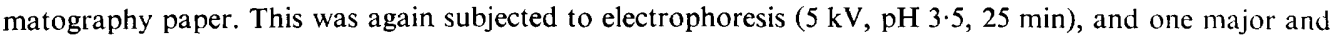
seven minor bands were found. The major band, glucaric acid, was eluted in $4.5 \mathrm{ml}$ water and contained $1.04 \times 10^{7}$ d.p.m. $\mathrm{ml}^{-1}$.

\section{RESULTS}

Isolation of a gar A mutant. Organisms deficient in the pathway of glucarate metabolism were isolated by the procedure of Kornberg \& Smith (1969). A suspension of strain K2.1.$2.22(p p c)$ grown in nutrient broth was spread on a plate containing $10 \mathrm{~mm}$-sodium acetate and $30 \mathrm{~mm}$-potassium glucarate as carbon sources. Glucarate, as well as other substrates catabolized to $\mathrm{C}_{3}$-compounds, inhibits the growth of $\mathrm{Ppc}^{-}$mutants on acetate. Mutants arising were presumably either $\mathrm{Ppc}^{+}$or had lost a component of the multistage pathway whereby glucarate entered the cells and gave rise to the $\mathrm{C}_{3}$-inhibitor of the glyoxylate cycle. 
Table 2. Specific activities of glucarate dehydratase in gar $^{+}$and garA strains of E. coli

Strair S AR115 $\left(\mathrm{gar}^{+}\right)$and AR114 ( $\left.g a r A\right)$ were grown in either nutrient broth, nutrient broth containirg $10 \mathrm{~mm}$-glucarate, or minimal medium containing amino acid growth requirements plus $30 \mathrm{mr}$-sodium glycollate. Glucarate dehydratase was assayed in the cell-free extracts; specific activities are expressed as $\mathrm{nmol} \mathrm{min}^{-1}$ (mg protein) $)^{-1}$.

\begin{tabular}{llr} 
Strain & \multicolumn{1}{c}{ Growth conditions } & $\begin{array}{r}\text { dehydratas } \\
\text { activity }\end{array}$ \\
AR115 & Nutrient broth & 19 \\
AR115 & Nutrient broth + glucarate & 900 \\
AR114 & Nutrient broth + glucarate & 28 \\
AR115 & Glycollate & 370 \\
AR114 & Glycollate & 4
\end{tabular}

Such mutants were tested for their ability to grow on acetate and acetate plus glucarate and for their inability to grow on other carbohydrates with or without acetate. One of these, AR109, and the parent strain K2.1.2.22 were transduced using bacteriophage Plkc grown on strain $\mathrm{K} 2.1 \mathrm{t}$ as donor, and $\mathrm{Ppc}^{+} \mathrm{Met}^{+}$colonies were selected on medium containing fructose, histidine, arginine, threonine and leucine to obtain strains AR114 ( $\left.g a r A p p c^{+}\right)$and AR115 $\left(\mathrm{gar}^{+} p p c^{+}\right)$. The gar $A$ mutation is unstable, and revertants appear with high frequency on plates containing glucarate as carbon source. Strain ARI14 is also unable to utilize galactarate as carbon source. Glucarate-positive strains grown on galactarate or glycollate adapt to growth on glucarate without a discernible lag.

$\left[{ }^{14} \mathrm{C}\right]$ Glucarate transport. $\left[{ }^{14} \mathrm{C}\right]$ Glucarate was taken up rapidly by strain AR $115\left(\mathrm{gar}^{+}\right)$ grown in nutrient broth containing glucarate. The apparent rate of uptake by cells in saturating external concentrations of glucarate was about $7 \mathrm{nmol} \mathrm{min}{ }^{-1}(\mathrm{mg} \text { dry mass) })^{-1}$ at $37{ }^{\circ} \mathrm{C}$ and was linear for $4 \mathrm{~min}$. Half the maximum velocity of glucarate transport was obtained with $16 \mu$ M-glucarate. The uptake of glucarate by cells was completely inhibited by 2 min preincubation with the uncoupler carbonyl cyanide $m$-chlorophenylhydrazone, at $25 \mu \mathrm{M}$ final concentration. The gar $A$ strain AR114 took up $\left[{ }^{14} \mathrm{C}\right]$ glucarate very slowly (less than $10 \%$ of the control rate) and little accumulated. This slow rate may be an overestimate of uptake by gar $A$ cells because of selection of $\mathrm{Gar}^{+}$revertants during growth in the presence of glucarate (see Table 3). Strains with the gar $B$ lesion did not take up glucarate.

Inhibition of glucarate uptake. Chemically related compounds were tested for their ability to inhibit glucarate transport, using a 75-fold excess of potential inhibitor. Of the compounds examined, only galactarate ( $98 \%$ inhibition) was extremely inhibitory. Gluconate $(4 \%)$, glucuronate $(9 \%)$, diaminopimelate $(7 \%)$, glutarate $(17 \%)$ and cystine $(29 \%)$ inhibited the rate of glucarate uptake by the amounts indicated.

Glucarate dehydratase. Glucarate dehydratase activity was measured in cell-free extracts of AR115 $\left(\mathrm{gar}^{+}\right)$and AR114 (garA) (Table 2). When the strains were grown in nutrient broth, the activities were very low. Addition of glucarate to the nutrient broth gave high activities for strain AR115, though not for strain AR114. Growth in minimal medium containing glycollate also gave medium activities with strain AR115, but not with strain AR114. No activity was detected in $\operatorname{gar} B$ strains grown in nutrient broth in the presence of glucarate.

Induction of glucarate transport and metabolism by glycollate. Since glycollate and glucarate are both metabolized via tartronate semialdehyde, we investigated whether growth on glycollate would induce the enzymes necessary for growth on glucarate. All the strains related to $\mathrm{Hfr}$ Cavalli were unable to grow with glycollate as carbon source, but strains AR $115\left(\mathrm{gar}^{+}\right)$and AR114 (gar A) were both able to do so. Strains AR 115 and AR114 grown on glycollate were incubated with glucarate plus glycollate, glycollate and glucarate; the cells were then harvested and assayed. The gar $^{+}$cells took up glucarate at similar rates [approx. $15 \mathrm{nmol} \mathrm{min}^{-1}$ (mg dry mass) ${ }^{-1}$ ], but the gar $A$ cells showed no transport activity (Table 3). 
Table 3. Uptake of $\left[{ }^{14} C\right]$ glucarate by gar ${ }^{+}$and garA strains of E. coli

Strains AR115 $\left(\mathrm{gar}^{+}\right)$and AR114 $(\operatorname{gar} A)$ were grown overnight on sodium glycollate as carbon source and then washed and suspended at an $A_{880}$ of 0.11 to 0.13 in $15 \mathrm{ml}$ medium containing salts, required amino acids, potassium glucarate $(6 \mathrm{~mm})$ and/or sodium glycollate $(20 \mathrm{~mm})$ as indicated below. After incubation at $37^{\circ} \mathrm{C}$ for 4 or $7 \mathrm{~h}$, cells were washed and $\left[{ }^{14} \mathrm{C}\right]$ glucarate transport was measured.

\begin{tabular}{|c|c|c|c|c|}
\hline \multirow[b]{2}{*}{ Strain } & \multicolumn{2}{|c|}{ Preincubation } & \multirow[b]{2}{*}{$\begin{array}{c}A_{680} \text { after } \\
\text { preincubation }\end{array}$} & \multirow{2}{*}{$\begin{array}{c}\text { Rate of glucarate } \\
\text { transport } \\
\text { [nmol (mg dry } \\
\text { mass })^{-1} \mathrm{~min}^{-1} \text { ] }\end{array}$} \\
\hline & Addition(s) & $\begin{array}{l}\text { Duration } \\
\text { (h) }\end{array}$ & & \\
\hline AR115 & $\begin{array}{l}\text { Glucarate } \\
\quad+\text { glycollate }\end{array}$ & 4 & $0 \cdot 46$ & 13 \\
\hline AR115 & Glycollate & 7 & $0 \cdot 26$ & 15 \\
\hline AR115 & Glucarate & 4 & 0.51 & 13 \\
\hline AR114 & $\begin{array}{l}\text { Glucarate } \\
\quad+\text { glycollate }\end{array}$ & 7 & $0 \cdot 23$ & $<0 \cdot 1$ \\
\hline AR 114 & Glycollate & 7 & 0.25 & $<0.1$ \\
\hline
\end{tabular}

Mapping the garA locus. Strain KL16.21 was mated with strain ARI14 and a His: recombinant (strain AR116) was obtained that was pts $G$ pts $M$ pts $F$ gar $A \mathrm{Gal}^{+}$. Interrupted mating experiments with strain $\mathrm{KL} 208$ as donor, selecting $\mathrm{PtsG}^{+}$recombinants, showed

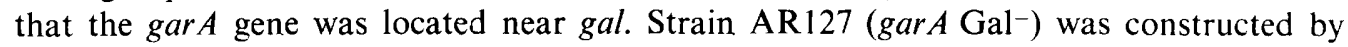
mating strain AR116 with strain PB1139, selecting for $\mathrm{Pps}^{+}$. Matings of this strain with the Hfr strains CSH68 and PB99 showed 79 to $97 \%$ linkage between gar $A$ and gal.

Bacteriophage PI grown on strain AR116 was used to transduce strain PB68, selecting $\mathrm{GalK}^{+}$recombinants. The yield of recombinants was very low, but of the 32 obtained, 11 were $\operatorname{gar} A$. The reason for the low yield of $\mathrm{Gal}^{+}$transductants is clear from the results of a transduction experiment in which bacteriophage P1 grown on strain AR114 was used to transduce strain $\mathrm{K} 1.1 .4(\mathrm{glt} A)$ to $\mathrm{Glt}^{+}$. Of 240 transductants examined, 67 were $\mathrm{Gal}^{-} \mathrm{Gar}^{-}$, $107 \mathrm{Gal}^{-} \mathrm{Gar}^{+}, 65 \mathrm{Gal}^{+} \mathrm{Gar}^{+}$and 1 was $\mathrm{Gal}^{+} \mathrm{Gar}^{-}$. The most plausible explanation of this result is that the order of the genes is. . lac ...glt A gal gar $A$. .trp ... and that strain AR 114 is genotypically gal but carries an extragenic suppressor of the lesion. Since strain AR 114 is ultimately derived from strain P678 it is reasonable that it should still carry components of the complex gal (gal-6) mutation (Morse et al., 1956; E. A. Adelberg, cited in Bachmann, 1972) and thus be genotypically gal but phenotypically $\mathrm{Gal}^{+}$.

The gar $A$ gene is not located between gal and bio since the galbio deletion strain JM759 (Jones-Mortimer \& Kornberg, 1976), which is garB, may be transduced to $\mathrm{Gar}^{+}$(using bacteriophage $\mathrm{P} 1$ grown on strain $\mathrm{P} 4 \mathrm{X}$ ) without becoming $\mathrm{Gal}^{+} \mathrm{Bio}^{+}$.

Mapping the garB locus. While attempting to map the gar $A$ locus we observed that $\mathrm{Hfr}$ Cavalli strains were glucarate-negative. Analysis of recombinants from a cross between strain K2.1t (thr leu) and strain JM1343 (mel gar B) suggested the gene order mel thr leu gar B. This was confirmed by a cross between strain AB1157 (thr leu gar ton $A^{+}$pro) and strain JM1447 (mel ara gar $B$ ton $A$ ). The results of this cross (Table 4) indicate that gar $B$ and ton $A$ are closely linked. Bacteriophage P1 was propagated on strains AT997 (dapC) and JM1506 $($ dap $D)$. Glucarate-positive transductants of a gar $B$ strain were selected, and 120 from each cross were scored for their diaminopimelate requirement. The dap $D$ gene was $96^{\circ}$ o cotransducible with gar $B$; the dapC gene was $87 \%$ cotransducible. When Pl grown on strain P4X (wild type) was used to transduce strain JM1448, all of the 80 glucarate-positive strains examined were $\operatorname{ton} A^{+}$as judged by their sensitivity to bacteriophage T5. The gar $B$ lesion thus maps at min $3 \cdot 5$.

Origin of the garB mutation. All the strains shown in Chart 5 of Bachmann (1972) from W6 to $\mathrm{K} 10$ and miscellaneous related strains were scored for their ability to utilize glucarate as carbon source and for their sensitivity to bacteriophage T5. Strains W6, Hfr Cavalli, 
Table 4. Analysis of Pro ${ }^{+}$recombinants from a cross between strain JM1447 (Hfr garB tonA) and strain $\mathrm{AB} 1157$ ( $\mathrm{F}^{-}$pro thr leu)

\begin{tabular}{cccccc}
\multicolumn{9}{c}{ Genotype } & & \\
thr & leu & gar $B$ & tonA & No. & Class \\
+ & + & - & - & 30 & Donor \\
- & - & + & + & 5 & Recipient \\
- & - & - & - & 5 &
\end{tabular}

$\operatorname{gar} B$ and $\operatorname{ton} A$ are closely linked, and the gene order is $\operatorname{thr} \operatorname{leu}(\operatorname{gar} B, \operatorname{ton} A) \operatorname{pro} A$.

W1895 and P4X were glucarate-positive and T5-sensitive; strains CS101 and K10 were glucarate-negative and T5-resistant.

\section{DISCUSSION}

A substrate translocation mechanism exists for glucarate transport in $E$. coli; it is sensitive to uncouplers of oxidative phosphorylation and is half-saturated by external glucarate concentrations of approximately $16 \mu \mathrm{M}$. The glucarate transport system is induced by glucarate, as is the enzyme glucarate dehydratase. It does not seem that internal glucarate is necessary for induction of the system, since glycollate also induces these functions.

Cells grown on galactarate are able to grow on glucarate without a lag, and vice versa. Glucarate dehydratase and galactarate dehydratase are both present when cells are grown either on glucarate or galactarate (Blumenthal, 1966; Blumenthal \& Jepson, 1966). These acidic carbohydrates may share a transport system, particularly as excess galactarate almost completely inhibited glucarate uptake in glucarate-grown cells. The glucarate transport system is not used extensively by either of the closely related monocarboxylic acid carbohydrates gluconate and glucuronate, judging from competition experiments.

One of the genes for glucarate utilization, termed gar $A$, has been located at about min 16 on the E. coli linkage map, and is cotransducible with gal. It appears that mutation of this gene is pleiotropic, since the transport of glucarate and glucarate dehydratase have much lower activities in both glucarate- and glycollate-induced gar $A$ cells; and the mutation also prevents growth on galactarate. Another gene, termed $\operatorname{gar} B$, has the same phenotype, but is located at about min 3.5. The garB lesion examined is probably a deletion of a gene (or genes) involved in glucarate catabolism and the gene for the T1,T5 receptor: it is stable, it cannot be separated by recombination from $\operatorname{ton} A$ and it appears to have arisen at the same time. Several hypotheses would account for the properties of these mutations: we have no evidence to distinguish between them.

The teleological question might be asked why E. coli possesses a catabolic pathway for glucarate. Perhaps the answer lies in the fact that normal humans excrete 4 to $30 \mu \mathrm{mol}$ D-glucarate $\mathrm{d}^{-1}$ in urine, and this is increased to values up to $300 \mu \mathrm{mol} \mathrm{d}^{-1}$ in people taking a variety of drugs including anticonvulsants (Hunter et al., 1971). Such increased excretion reflects stimulation of the hepatic pathway of glucuronate metabolism (Aarts, 1971). As an occasional unwelcome coloniser of the bladder, $E$. coli might have evolved the ability to catabolize glucarate, particularly as physiological concentrations are similar to the $K_{\mathrm{m}}$ of glucarate transport. If so, the glucose content of urine $\left(250 \mathrm{mg} \mathrm{d}^{-1}\right)$ would probably repress glucarate catabolizing enzymes at first, until bacterial numbers increase to the extent where glucose is used up and less favoured energy sources are in demand.

We are grateful to Dr B. Bachmann for providing strains. 


\section{REFERENCES}

AARTs, E. M. (1971). D-Glucaric acid excretion as a test for hepatic enzyme induction. Lancet i, 85 . Ashworth, J. M. \& KornberG, H. L. (1966). The anaplerotic fixation of carbon dioxide by Escherichia coli. Proceedings of the Royal Society B165, 179-188.

BÄCHI, B. \& KoRNBERG, H. L. (1975). Utilisation of gluconate by Escherichia coli: a role of adenosine $3^{\prime}: 5^{\prime}$-cyclic monophosphate in the induction of gluconate catabolism. Biochemical Journal 150, 123-128.

Bachmann, B. J. (1972). Pedigrees of some mutant strains of Escherichia coli K12. Bacteriological Reviews 36, 525-557.

Bachmann, B. J., Low, K. B. \& TAylor, A. L. (1976). Recalibrated linkage map of Escherichia coli K12. Bacteriological Reviews 40, 116-167.

Blumenthal, H. J. (1966). D-Glucarate dehydrase. Methods in Enzymology 9, 660-665.

Blumenthal, H. J. \& Fish, D. C. (1963). Bacterial conversion of D-glucarate to glycerate and pyruvate. Biochemical and Biophysical Research Communications 11, 239-243.

Blumenthal, H. J. \& Jepson, T. (1966). Galactarate dehydrase. Methods in Enzymology 9, 665-669.

BRICE, C. B. \& KorNberG, H. L. (1967). Location of a gene specifying phosphopyruvate synthase activity on the genome of Escherichia coli K12. Proceedings of the Royal Society B168, 281-292.

Bukhari, A. I. \& TAYlor, A. L. (1971). Genetic analysis of diaminopimelic acid- and lysinerequiring mutants of Escherichia coli. Journal of Bacteriology 105, 844-854.
Ferenci, T. \& Kornberg, H. L. (1974). The role of phosphotransferase-mediated syntheses of fructose 1-phosphate and fructose 6-phosphate in the growth of Escherichia coli on fructose. Proceedings of the Royal Society B187, 105-119.

Henderson, P. J. F., Giddens, R. A. \& JonesMortimer, M. C. (1977). Transport of galactose, glucose and their molecular analogues by Escherichia coli K12. Biochemical Journal 162, 309-320.

Hunter, J., Carrella, M., Maxwell, J. D., Stewart, D. A. \& Williams, R. (1971). Urinary D-glucaric acid excretion as a test for hepatic enzyme induction in man. Lancet i, 572-575.

Jones-Mortimer, M. C. \& Kornberg, H. L. (1976). Uptake of fructose by the sorbitol phosphotransferase of Escherichia coli K12. Journal of General Microbiology 96, 383-391.

Kornberg, H. L. \& Smith, J. (1969). Genetic control of hexose phosphate uptake by Escherichia coli. Nature, London 224, 1261-1262.

Low, K. B. (1973). Rapid mapping of conditional and auxotrophic mutants of Escherichia coli $\mathrm{K} 12$. Journal of Bacteriology 113, 798-812.

Mehltretter, C. L. (1963). D-Glucaric acid: potassium hydrogen D-glucarate and D-glucaro6,3-lactone. Methods in Carbohydrate Chemistry 2, 46-48.

Miller, J. H. (1972). Experiments in Molecular Genetics. New York: Cold Spring Harbor Laboratory.

Morse, M. L., Lederberg, E. M. \& LederberG, J. (1956). Transductional heterogenotes in Escherichia coli. Genetics 41, 758-779. 